\title{
The Impact of Community
}

Service-Learning in a Rural

Community on Undergraduate

Students

Lauren R. Paulson

Allegheny College

\section{Recommended Citation:}

Paulson, L.R. (2018). The impact of community service-learning in a rural community on undergraduate students. International Journal of Research on Service-Learning and Community Engagement, 6(1), Article 12. 


\title{
The Impact of Community Service-Learning in a Rural Community on Undergraduate Students
}

\author{
Lauren R. Paulson \\ Allegheny College
}

\begin{abstract}
The purpose of the mixed-methods action research study discussed in this article was to examine the impact of community service-learning (CSL) in a rural community on 45 undergraduate students enrolled in a clinical psychology course. The study sought to develop a new contextualized grounded theory and richer understanding of the phenomenon of CSL in a rural community with undergraduate psychology students. Qualitative data were collected at multiple stages through a reflective paper and two open-ended questions administered to students at the end of the CSL experience. In addition, individual interviews were conducted with the CSL partners. Quantitative data were collected through two surveys (pre- and post-CSL) to measure outcomes related to specific course objectives. Overall, the qualitative results suggested that the CSL component aligned well with the clinical psychology course and influenced the students' academic, personal, social, civic, and diversity learning outcomes. In addition, students reported experiences that were unique to working in the rural context, while the community partners shared both the benefits and challenges of working with the students. The implications of the findings and practical recommendations are discussed.
\end{abstract}

Keywords: service-learning, community engagement, clinical psychology, rural, undergraduate

The foundation of a liberal arts education is to teach not only broad knowledge and practical skills, but also personal and civic responsibility and integrative learning. Community service-learning (CSL) is a pedagogical tool that can be used to help meet this lofty mission. It has been well established that experiential experiences, such as CSL, can enhance academic, personal, social, and civic outcomes for students and provide opportunities to apply classroom knowledge in an ecological setting (Celio, Durlak, \& Dymnicki, 2011; Conway, Amel, \& Gerwien, 2009; Jacobson, Oravecz, Falk, \& Osteen, 2011; Kuh, 2008; O'Neill, 2012). CSL presents an ideal pedagogical approach to encourage students to be active learners and to address community needs (Slavkin, 2007). However, despite several decades of scholarship on the positive impacts of CSL on undergraduate students, findings from these previous studies have not yielded large effects, and the measured impacts on multicultural skills have been inconsistent. Additionally, there have been no published studies on CSL in a rural context involving psychology students. Therefore, purposefully integrating CSL with discipline-specific theory and research makes intuitive sense. The purpose of this mixed-methods action research study was to examine the experiences of undergraduate students who took a CSL course in clinical psychology in a rural area.

\section{The Rural Context}

It is important to explore the impact of CSL in a rural context, as rural communities face unique challenges compared to their urban counterparts. It has been suggested that rural areas and geographical locations comprise distinct cultures. In fact, the Committee on Rural Health was formed by the American Psychological Association (APA) in recognition of the unique concerns and behavioral health needs of rural communities and their residents. However, not all rural locations are the same, and it is imperative to not overgeneralize from one area to the next. Specifically, in rural areas, resources are scarce, and residents have less access to employment and adequate insurance coverage (Gale \& Lambert, 2006; Wagenfeld, 2003). While the rate of mental disorders in rural areas is comparable to that in urban areas, suicide rates, alcohol abuse, and chronic illness have been found to be higher in rural areas (Grant et al., 2015; Mohatt, Bradley, Adams, \& Morris, 2006). Adding to this risk is a shortage of rural mental health providers since rural areas find it difficult to recruit and retain mental health professionals; therefore, residents' mental 
2 | International Journal of Research on Service-Learning and Community Engagement

health concerns are often treated by local primary care physicians (Campbell, Kearns, \& Patchin, 2006; Schank \& Skovholt, 2006; Werth, Hastings, \& Riding-Malon, 2010). Rural individuals may put off treatment because they do not know the available options, have negative views about treatment, or have a fear of being stigmatized (Larson \& Corrigan, 2010). People in tight-knit rural communities may turn more often to informal networks of family, friends, and church leaders for support in addressing mental health problems compared to their urban counterparts (Fox, Blank, Rovnyak, \& Barnett, 2001; Gale \& Lambert, 2006; Helbok, 2003; Weigel \& Baker, 2002). Additional stressors that rural residents experience include poor road conditions, bad weather, lack of transportation, and long travel distances to receive mental health services (Barbopoulos \& Clark, 2003; Gale \& Deprez, 2003; Sawyer, Gale, \& Lambert, 2006; Smith, 2003). Some rural areas in the United States also have higher rates of poverty than urban areas (U.S. Census Bureau, 2016a). Indeed, each of the aforementioned issues can inhibit opportunities for adequate mental health care in rural areas.

Rural mental health practitioners also face unique ethical issues related to limits to professional competence, multiple relationships (i.e., conflicts of interest), lack of resources, increased risk of burnout, confidentiality, competence in assessment, and challenges with informed consent (Paulson, 2010; Werth et al., 2010). Therefore, one could argue that the partnerships and collaborations established through CSL are even more critical in rural areas, where resources, mental health providers, and services are limited, and where the mutual benefit of CSL may be enhanced.

\section{Why Clinical Psychology?}

In an effort to improve student learning, the APA (2013) has advocated for the integration of CSL into undergraduate psychology curricula. Previous studies have explored CSL in other undergraduate preprofessional courses and have identified positive outcomes. For example, family studies and social work students engaged in CSL demonstrated positive academic and career outcomes (Jacobson et. al., 2011; Lemieux \& Allen, 2007); occupational and speech pathology students reported improved academic outcomes (Jones, McAllister, \& Lyle, 2016); and pharmacy and medical students described their CSL as a transformative learning experience that helped them to begin developing an understanding and skills for working more effectively with clients in urban underserved settings (Clark, McKague, McKay, \& Ramsden, 2015). However, as noted earlier, there has been no published research on the impact of CSL on undergraduate clinical psychology students.

As Ozorak (2003) said, "psychology and service are about people" (p. 21), and clinical psychology focuses on developing a comprehensive understanding of human functioning. CSL connects naturally with clinical psychology since it centers on improving communication and interpersonal skills and empathy, providing a deeper understanding of theoretical concepts, facilitating increased commitment to social responsibility, and increasing awareness of stereotypes, privilege, and tolerance for diversity (Catlett \& Proweller, 2011; Jones, Robbins, \& LePeau, 2011; Yeh, 2010). One unique feature of CSL in a clinical psychology class is that the students have direct contact with clients, an element missing from other reviewed mental health studies (Lemieux \& Allen, 2007).

\section{The Clinical Psychology Course}

Because every CSL experience is different, and to allow for more accurate interpretation of study the outcomes, it is important to first describe the context of the specific CSL course on which this research focused. The clinical psychology class was a hands-on, upper level course that provided an overview of the therapies, treatments, and practice of clinical psychology. The course is an elective in the psychology department of a small, private, liberal arts college located in a rural area in the eastern United States. The class was flagged as a CSL course, and students were therefore required to receive instructor permission to register, ensuring that they were well-advised of the CSL requirements and expectations. The class was capped at 15 students each semester to allow for greater discussion, reflection, and overall sense of community (Crabtree, 2008). The relatively small class size also allowed the instructor to more easily provide support and specific feedback throughout the semester. 
The theoretical and pedagogical roots of the class and CSL were grounded in experiential learning, with an emphasis on the research and writings of Dewey (1938) and Kolb (1984), who called for "learning by doing." The goal of the course was to move students beyond the cognitive domain of the classroom to the "real world" of action, offering them an avenue to practice clinical and communication skills and empathy, and to gain valuable professional experience (Yeh, 2010); in essence, the CSL served as another "text" for the class. The course objectives were as follows: to enrich the curriculum and enhance student learning by joining theory with action and helping students understand the relevance of the academic subject to the real world; to explore the helping alliance - the basic relationship on which the actual work of counseling rests (Greenson, 1967); to develop and apply micro-counseling skills, empathic responses, and observation and interview skills in relation to diverse individuals living with various challenges; to develop an awareness of how disorders, structures, and systems affect individuals' lives; and to provide meaningful and relevant service to local community partners.

\section{Clinical Psychology and Power, Privilege, and Difference}

The APA's (2013) Guidelines for the Undergraduate Psychology Majors 2.0 focus primarily on promoting social responsibility in a diverse world. Components of this overarching goal include building and enhancing interpersonal relationships and adopting values that build community at the local, national, and global levels (APA, 2013). It has been well established that CSL increases student's awareness of privilege, reduces negative stereotypes, and increases tolerance for diversity (Williams \& Melchiori, 2013). Therefore, the power, privilege, and difference (PPD) component was an integral element of the CSL course in this study. The clinical psychology textbook used in the class centered mainly on intra- and interpersonal relationships and the microsystem, while one of the foundational goals of CSL was to bring the macrosystem into the equation. As Bronfenbrenner $(1979,2005)$ maintained, the relationship between the person and the environment is dynamic, and the development of the person cannot be separated from the social networks in which they are embedded.

\section{The Present Study}

The purpose of this mixed-methods action research study was to examine the impact of CSL in a rural community on 45 undergraduate students enrolled in a clinical psychology course. There is a need for research that examines the outcomes of CSL in discipline-specific undergraduate courses and that provide a framework for implementing such courses in rural communities. This study built upon the general framework of several well-documented CSL sources (Billig \& Furco, 2002; Eyler \& Giles, 1999; Eyler, Giles, Stenson, \& Gray, 2001; Whitley, 2014) that were embedded in the rural and clinical psychology course context. The general framework includes four categories: (a) academic and career outcomes, (b) personal outcomes, (c) social and civic outcomes, and (d) diversity and multicultural/intercultural outcomes.

As is common in action research, other stakeholders, specifically CSL partners, were interviewed in this study to help better understand the impact of CSL and ensure that the partners' voices were grounded in the conversation. In fact, this may be even more important in a rural area, where building collaboration is especially relevant (Paulson, 2010). Including a qualitative and descriptive methodology allowed the theoretical constructs to emerge from the data, allowing for a better understanding and contextualization of the student experiences - which quantitative surveys alone might have failed to detect (Strauss \& Corbin, 1998). This mixed-methods approach can also account for and capture the unpredictability of CSL (Deeley, 2010).

\section{Method}

\section{Research Participants}

Participants included 45 undergraduate students (out of a total of 52 registered students) who voluntarily enrolled in an undergraduate clinical psychology course at a small, private, liberal arts college in a rural area. Data were collected over four consecutive semesters (two years). The majority of students at the 
4 | International Journal of Research on Service-Learning and Community Engagement

college are White (69\%). The median family income for new, first-time, full-time, first-year students who submitted a FAFSA in 2016 was $\$ 84,800$. For comparison, the 2016 U.S. median household income was $\$ 57,617$, and the median income of the local town in which the college is situated was $\$ 34,826$, with $24 \%$ of the residents living in poverty (U.S. Census Bureau, 2016b). Table 1 summarizes the demographic information for the study participants.

Table 1. Gender, Ethnicity, Previous CSL Experience, Year in School, and Major ( $\mathrm{N}=45)$

\begin{tabular}{ll}
\hline Variable & Participants, N (\%) \\
\hline Gender & $17(38 \%)$ \\
Male & $28(62 \%)$ \\
Female & \\
Ethnicity & $37(82 \%)$ \\
White & $4(9 \%)$ \\
African American & $2(4 \%)$ \\
Asian American & $2(4 \%)$ \\
Hispanic & \\
Previous CSL Experience & 4 \\
Yes & 41 \\
No & \\
Year in School & $3(7 \%)$ \\
Second & $23(51 \%)$ \\
Third & $19(42 \%)$ \\
Fourth & \\
Major & $31(69 \%)$ \\
Psychology & $6(13 \%)$ \\
Neuroscience & $5(11 \%)$ \\
Biology & $3(7 \%)$ \\
Religious Studies & \\
\hline
\end{tabular}

\section{Measures}

To enhance the trustworthiness of the data, this action research study employed a mixed-methods approach to data collection and analysis. Qualitative data were collected each semester in sequential stages through a reflective paper, two open-ended questions administered at the end of the CSL experience, and individual interviews with the CSL partners after the end of the semester. Quantitative data related to empathy and PPD were collected using two surveys, both pre- and post-CSL. The rationale for the quantitative surveys was to examine outcomes that had been assessed in previous research and to measure variables that were closely related to the course objectives. One of the course goals was to enhance empathy since empathy is one of the foundational characteristics of helping relationships. In addition, due to inconsistencies of PPD outcomes in previous research, the course also focused on addressing issues related to PPD in the mental health field.

\section{Critical Reflection Papers}

Critical reflection is key to the success of CSL in that it helps connect coursework with students' 
experiences at their respective CSL sites (Keen \& Hall, 2009). The students in the course were assigned a term paper and were asked to discuss the lessons they learned from their CSL experiences and what they learned about themselves.

\section{End-of-semester Evaluation}

Participants were asked the following two open-ended questions at the end of CSL experience: (1) Do you feel the course objectives and the CSL component fit well together? Why or why not? (2) To what extent did the CSL experience meet your expectations? The goal was for the open-endedness of the questions to encourage students to answer freely.

\section{CSL Provider Interviews}

After obtaining consent from study participants, the primary researcher conducted individual interviews with six of the seven CSL providers in order to gain insight into their perspectives. All interviews were audio recorded and transcribed word for word. The CSL partners were asked the following questions: What were the benefits and challenges of the CE partnership? As a result of the CE partnership, have your perceptions of [the college's] students changed? How satisfied are you with the overall CE partnership and experience? Do you have any suggestions for enhancing this partnership to benefit you, the community, the college, and/or the students?

\section{Interpersonal Reactivity Index}

The Interpersonal Reactivity Index (IRI; Davis, 1980) was used to measure participants' empathy. One of the most widely used and comprehensive measures of multidimensional empathy (Cliffordson, 2002), the IRI is a 28-item, 5-point Likert scale that consists of four subscales: Perspective Taking (PT), Empathic Concern (EC), Fantasy Scale (FS), and Personal Distress (PD). Example items include, "When I'm upset at someone, I usually try to put myself in his shoes for a while" and "When I see someone being taken advantage of, I feel kind of protective towards them." The IRI has demonstrated greater internal reliability, test-retest reliability, and construct validity compared to other empathy measures (Davis, 1980). In the current study, the Cronbach's alpha coefficient was 0.78.

\section{Munroe Multicultural Attitude Scale Questionnaire}

The Munroe Multicultural Attitude Scale Questionnaire (MASQUE; Munroe \& Pearson, 2006) was used to measure changes in multicultural attitudes, including issues related to socioeconomic status (SES), ethnicity, gender, religion, sexual orientation, and language. The 18-item MASQUE consists of 6-point Likert scales in three domains: know, care, and act. Example items include, "I realize that racism exists," "I understand that gender-based inequalities exist," and "I am sensitive toward people of every financial status." Few instruments have been developed to measure constructs related to PPD in college students; however, the internal reliability of the MASQUE was found to be adequate for research purposes (Munroe \& Pearson, 2006). In the current study, the Cronbach's alpha coefficient was 0.65.

\section{Procedure}

\section{Creating the CSL Experience}

After teaching the class for nine semesters, the course was flagged as a CSL course. Formal preparation began the spring semester before the scheduled fall course. The instructor met with the only CSL resource on the campus at the time to refine the syllabus, learning objectives, and assignments, and to solicit additional resources and possible CSL sites. Emails were sent to prospective sites to determine interest in partnering with the clinical psychology instructor, who then met with each contact in person to discuss the goals, course objectives, and the provider's needs. This process took most of the summer prior to the fall semester. During this period, the instructor also spent a considerable amount of time preparing the sites, 
6 | International Journal of Research on Service-Learning and Community Engagement

refining the course objectives and assignments, and reading about CSL (e.g., APA, 2013; Aronson et al., 2005; Billig \& Furco, 2002; Celio et al., 2011; Conway et al., 2009; Eyler \& Giles, 1999; Jameson, Clayton, \& Bringle, 2008; Whitley, 2014).

Part of the success of a CSL course is that it represents a good "fit" between the course goals and the needs of the placement site. However, achieving this alignment posed a challenge due to issues with confidentiality, the nature of clinical psychology itself, and the fact that the college is located in a rural area. All placements were at social-service-related sites, including women's services, a private outpatient facility, a youth residential facility, a youth partial hospitalization program, a community mental health awareness program, and an independent living/transitional housing program. Due to the challenges of finding relevant sites in a rural community, the goal for the CSL component to address the clinical and/or PPD components of the course.

\section{Student Preparation for CSL}

After the study gained IRB approval, enrolled students were emailed an informed consent form and a link to the online pre-CSL assessments (i.e., IRI and MASQUE). Participation was voluntary, and 45 out of 52 students opted to complete all of the assessments. To maintain student anonymity, students were asked to provide a 4-digit code to link to the pre- and post-tests. Data were collected over four semesters, and the same instructor taught all of the classes.

The service providers led an orientation session during the second week of classes during which they reviewed their respective programs and expectations. In order to maximize autonomy, students chose their top three sites, and groups of two to four students were assigned to each site. The students were assigned PPD readings and were required to complete an initial group interview with their site supervisor the following week. Students were given the opportunity to meet in groups during class, with instructor facilitation, to develop interview questions. In addition, the college's Director of Community Service and Service-Learning and a student engagement fellow delivered a class presentation focusing on the philosophy of CSL, the importance of community, and addressing local stereotypes (i.e., "townies"). The instructor prioritized making the expectations of the course explicit and clear from the start, in hopes of increasing the chances of a positive outcome for all parties involved and not rupturing the relationships formed with local rural community members.

The student groups then met with the site supervisors and completed a CSL agreement, which included collaborative learning goals and expectations, and which was signed by all parties. The students were required to complete two hours of CSL per week for 12 weeks, working directly with the sites to negotiate their schedules. In addition to the class discussions and assignments (described in a later section), the instructor met one-on-one with each student mid-semester to process their experiences and discuss any questions or concerns they might have had. The instructor also contacted each site after the first week of CSL, mid-semester, and met with the site supervisors at the end of the semester to process their experiences.

\section{Assignment}

The CSL was integrated into the entire course and reflected in the learning objectives. The instructor wanted to use CSL as a pedagogical tool to help bring the human element into a traditional classroom. In order to maximize learning and make connections among research, theory, and the CSL, the instructor incorporated various homework assignments and classroom activities and discussions, with a specific focus on PPD and the helping relationship. The class discussions allowed the instructor to assess the effectiveness of the CSL site placements and to assist students who were struggling to make explicit connections between the course and the CSL component. In addition, the students met in groups to reflect on their experiences, allowing them to hear about others' experiences, learn from different perspectives, and work cognitively and emotionally through their experiences.

In order to enhance students' learning and help them make connections to their CSL experiences, students were given the opportunity for personal reflection. Students wrote weekly reflections in online 
journals, and they were given strong and explicit feedback from the instructor throughout the semester. Following the framework of the DEAL (describe, examine, and articulate learning) model for critical reflection (Ash \& Clayton, 2009), most of the weekly reflections included critical-thinking prompts related to the course content that allowed students a structured reflective experience. In addition, in an effort to enhance a sense of community and provide support to the students, a student fellow met with the students, without the instructor, during group reflections to act as a peer resource.

Student groups were also assigned an end-of-semester class presentation and an individual final paper and reflection. The paper focused on the students' ability to integrate their CSL with psychological research and theory, engage in critical thinking, and demonstrate professionalism and commitment to the CSL experience. The reflective piece included the most important learning lessons from the CSL, a critical evaluation of their own development, and how the experience connected to their long-term career goals. Students were also challenged to think about what might have interfered with their learning or engagement.

\section{Data Analysis}

A mixed-methods approach informed the analysis of both qualitative and quantitative data collected during the study. The data from the two open-ended responses were uploaded into NVivo and analyzed, then the reflective papers were analyzed using the constant comparative method, which is central to grounded theory (Creswell, 1994); that is, the data were systematically and continuously compared throughout the study; therefore, similarities and differences were noted, and sequential comparisons were made during collection and coding. All personal identifiers, such as specific names of people and places, were removed from the data in order to maintain student confidentiality.

Initial data analysis began with open coding, during which major descriptive categories were generated. Modified axial coding was then used to position categories within the general theoretical model discussed earlier. According to Creswell (1994), after open coding, axial coding allows the researcher to sort, synthesize, and organize large amounts of data. This strategy brings the data back into a "coherent whole" in the context in which the category is embedded (Strauss \& Corbin, 1998, p. 125). The final step comprised selective coding, whereby interactions of categories were assembled and core categories were chosen. At this point, data saturation occurred since no more new information emerged from the data. Through the emergence of these major categories, a theory could be developed about the categories in relation to the rural context and a clinical psychology course.

Recognizing that qualitative research is subjective, the researcher maintained a record of continuous memo writing throughout the study and noted contradictory findings. In addition, the data were analyzed further by a second, independent rating of the responses from a mental health professional with no ties to the study. There were two responses in which there was an initial lack of agreement, and both parties worked through the agreement until a consensus was reached. Finally, independent and pairedsamples t-tests were conducted to evaluate the impact of CSL on student scores on all of the subscales of the IRI and MASQUE across all semesters and for each separate semester.

\section{Results}

The core responses that emerged from the data and that were then situated within the general framework are reviewed in the following sections. It is important to note that there was considerable overlap and connection among the core categories; however, the researcher attempted to collapse the themes into this general framework in the context of the clinical psychology class and rural community. A summary of the qualitative responses and the quantitative data, both pre- and post-CSL, are reviewed in the following sections.

\section{Academic and Career Outcomes}

The academic and career outcomes - the most frequently measured variables in CSL research-included learning the course content, applying the course content, academic skills, academic identity, and vocational development. This was an important variable to measure, as the main goal of this course was for students 
8 | International Journal of Research on Service-Learning and Community Engagement

to learn and apply theoretical concepts to their CSL experience. Student responses supported this outcome in that the CSL experience provided the opportunity to learn and apply the course content, and allowed for a deeper understanding of course material (see Table 2). In an item-analysis of the data (using NVivo), the words apply, application, and hands on appeared most frequently.

Table 2. Student Comments on Academic and Career Outcomes

\begin{tabular}{ll}
$\begin{array}{l}\text { Outcome } \\
\text { Category }\end{array}$ & Comments \\
\hline Application & "I was surprised how much I took from my CE site to class and vice versa. They both \\
applied to each other and I was learning from lecture and community engagement." & "I found myself applying many of the course objectives to my CE site, and found that I \\
& didn't have to study the material as much because I had been using it every visit." \\
& "It was really nice to see the connection from the classroom to the workplace." \\
& "Being immersed in a clinical setting, I learned first-hand about the therapeutic alliance \\
& and therapy."
\end{tabular}

Observation "This was first real experience working with people with mental disorders. This helped me to see the person behind his or her condition, and realize that they are humans just like everyone else."

Enhanced "Community engagement=best experience of academic career."

Learning

"I feel as though I understand and remember the material more when I see it actually happening at my site."

"I believe the content learned in class goes hand-in-hand with applying it to the outside world. Without the CE site the class would not have been the same."

"The CSL made the course material much easier to understand as I was immersed in it every week."

The Rural "Being in a rural community makes it hard to avoid clients outside of the professional Context setting. [This town] is a small town, and most of the clients live directly in town. It is not uncommon for students and other staff member to run into clients outside of [the agency]. It is important to learn to navigate these boundaries in a rural area."

"Small rural community like [ours] have the potential for dual relationships. Personally, I didn't believe that this would be an issues for me....I was sorely mistaken. I actually sat next to one of the girls [at the site] in class the previous year and I recognized her at the school. I knew I would be breaching confidentiality if I would've said anything to her outside of the counseling center." "One important aspect that we talked all about in class was [professional] burnout. I was able to talk to [my supervisor] and gained some valuable information on how she protects herself from burnout, many of them related back to the methods we discussed in class."

"I experienced how easily clients can trigger thoughts and emotions in an active listener. This led me to be more aware of my own emotions and moods before each 


\begin{tabular}{ll}
\hline & session...this is important to prevent burnout and secondary trauma." \\
Career & "I was also given a very good insight in the field I am hoping to work in." \\
Outcomes & "I was able to work with kids in a clinical setting which I always wanted to be able to \\
& do." \\
& "The CE experience contributed to my growing as a potential worker in the mental \\
& health field."
\end{tabular}

By applying these concepts, students were able to make meaningful cognitive connections between course content and their sites. Students commented that they were able to observe specific course content at their sites such as intake exams, mental status exams, and therapy techniques with both groups and individuals. Most of the sites provided the students with a first-hand opportunity to see a therapeutic environment in action. Many students cited seeing theories-such as humanistic, solution-focused, behavioral, feminist, CBT, DBT, etc.-in action.

The majority of students indicated that the course objectives and their CSL experience enhanced their learning beyond the classroom and textbook, and that they were able to make explicit connections to each. Students used words such as reinforced, solidified, and made it real. Students also witnessed firsthand the ethical concerns rural mental health professionals face related to issues with boundaries, dual relationships, self-care, compassion fatigue, and secondary trauma, among others. In fact, one student wrote an entire paper on compassion fatigue and burnout in a rural area.

However, in order to account for threats of validity, it is important when making comparisons in data to reflexively examine negative case examples, or instances that do not "fit" (Denzin \& Lincoln, 2011). Participants made a few statements that did not support the supposition that the CSL component and course objectives were aligned; such comments included the following: "The site I went to however was a little bit difficult to apply any direct information from the book and the teachings since it wasn't exactly a true clinical place but it was enough to work with and connections were made"; "Although our site wasn't very clinical, we learned empathy and how to be nonjudgmental when working with people who are different," and finally; and "Although not all course concepts fit into my personal experience at my [CSL] site I think the majority of the objectives in class had relevance to my work at my [CSL] site."

\section{Personal Outcomes}

Personal outcomes focus on the influence of the CSL course on the growth and development of the participants in the following areas: personal growth, identity development and formation, selfunderstanding and efficacy, moral development, leadership, spirituality, well-being, and sense of purpose (Whitley, 2014). The most frequent comments related to this outcome involved the personal meaning and impact of the CSL on the student as a person (see Table 3 for student comments).

\section{Social and Civic Outcomes}

Social and civic outcomes include communication and interpersonal skills, empathy, social self-efficacy, civic responsibility, civic engagement, social justice, and civic skills and knowledge (Whitley, 2014). Student participants indicated addressing several areas of social development and even commented on using micro-counseling skills at their sites.

Paired-samples t-tests were conducted to evaluate the impact of CSL on student empathy scores on all of the subscales of the IRI across all of the semesters and for each separate semester. There were no statistically significant changes in scores from Time 1 to Time 2 in any of the paired-samples ttests. However, there was an overall trend of increased mean scores across all subscales from Time 1 to 
10 | International Journal of Research on Service-Learning and Community Engagement

Table 3. Student Comments on Personal Outcomes

\begin{tabular}{ll}
\hline $\begin{array}{l}\text { Outcome } \\
\text { Category }\end{array}$ & Comments \\
\hline Meaning & "I didn't really think it would have an impact on me or help with my in-class learning but I \\
& was wrong about all of that." \\
& "It was a great and enriching experience. As a person I have grown tremendously, and I \\
& feel like this is one of the best learning outcomes possible, the CSL experience ended up \\
& providing much more of an impact on me as a person than I initially expected it to be." \\
& "It helped solidify my understanding of the world as a whole." \\
& "My CSL was a very enriching one in many aspects of my existence. It forced me to go \\
& outside of my comfort zone and deal with situations I never had in other settings. Up until \\
& this point I had minimal experience working with older people outside of my family...I \\
& feel my communication skills have been enriched because of this experience." \\
& "I never expected that I would be placed in such an environment where I would see such \\
& strength from individuals whom have been affected by such traumatic experiences such as \\
& domestic violence!"
\end{tabular}

Time 2. There is substantial research supporting gender differences in empathy, and the published norms of the IRI were separated by gender; therefore, analyses were run both together and separately by gender. An independent-samples t-test was conducted to compare the Empathic Concern subscales of the IRI between males and females. There was a significant difference in scores for males $(M=22.11, S D=3.42)$ and females $(M=24.14, S D=2.70 ; t(43)=-2.20, p=0.033$, two-tailed $)$. The effect size was moderate, $d=0.65$. In other words, females demonstrated significantly higher scores on EC compared to males, postCSL.

Regarding civic outcomes, students indicated increased civic knowledge, attitudes of civic responsibility, and behavioral intentions in their remarks, with several students commenting that they planned to continue service after the end of their semester. In addition, the theme of connecting with the rural community emerged throughout the data analysis (see Table 4).

\section{Diversity and Multicultural/Intercultural Outcomes}

The diversity and multicultural/intercultural outcomes, which were intimately tied to the course PPD objectives, included personal privilege awareness, reduced stereotypes, perspective taking, diversity awareness, increased tolerance, and universality orientation (Whitley, 2014). In an item analysis of the data using NVivo, PPD was the item that appeared most frequently.

Regarding PPD concerns specific to a rural area, students made several comments about the impact of poverty, low SES, and lack of resources. Several students commented about the lack of resources and nighttime and weekend childcare, which made it difficult for clients to secure jobs. Several students discussed the need to acknowledge their own financial privilege during the CSL experience. For example, students who worked with children spoke about how the children shared concerns related to money, Christmas presents, or whether their insurance would cover doctor's appointments - concerns which the students admitted they did not think about as children (see Table 5 for student comments). 
Table 4. Student Comments on Social and Civic Outcomes

\section{Outcome \\ Category \\ Comments}

Social Outcomes

"In [our readings] we learned that to truly understand where someone comes from is go out there and put ourselves in another, less fortunate person's shoes and learn from them...this is exactly what I did during my [CSL] experience."

"I feel I reached higher levels of empathy and became a better listener."

"I was able to observe what is involved in a clinical practice from an insider perspective, which naturally involves effective communication with community members/people of different ethnicities, SES backgrounds, education levels, etc."

Civic Outcomes "I learned more about the community and the clients at my site."

"I feel I made a difference in people's lives."

"I now appreciate my community and want to help the people."

"It opened my eyes to the opportunities our community has to offer and I hope I gave a lot in the process."

"I can honestly say that I loved my experience and am looking forward to continuing to do service within the community."

"I think the experience was extremely beneficial to me and I gained valuable knowledge and insight into my organization and how important it is to get involved with your community. I thought that this was going to be a burden, but I found myself looking forward to going to my site. I did not expect to connect with the people of [this town] the way I did."

The Rural Context "This experience was eye opening for me and really allowed me to create a stronger connection and appreciation to [the rural] community and its citizens that will be useful for me in graduate school and beyond."

"My ideas about the local community and its people have changed. I now personally know some the people who live downtown and they are not much different than myself, even if they have entirely different lives."

"Being 21 and in college, I think some of my automatic thoughts can get me into trouble...thoughts about the [rural] community were proven wrong during my time at [my site]. Most students have stereotypes about the 'townies' and seeing all the different backgrounds in group [therapy] really put that into perspective for me." 
12 International Journal of Research on Service-Learning and Community Engagement

Table 5. Student Comments on Diversity and Multicultural/Intercultural Outcomes

\section{Outcome Category Comments}

Application

"The site provided firm examples for us of inequities due to SES, race, gender, religion, sexual orientation, it made it easy to understand complex topics related to PPD and biases while engaged."

"We learned empathy and how to be nonjudgmental when working with people who are different."

"I got to hear of issues relating to PPD that I wouldn't have thought of before on my own."

"I learned a lot from the experience and I believe that I was able to challenge my prior stereotypes about the community and about clinical psychology in general."

The Rural Context "This type of programming is especially critical in smaller communities....where people with mental health problems might be feeling isolated and

disempowered.... and there are not as many resources available."

"Most of the clients are of a low SES...students who go there to help have to be sensitive about this because to most of them take this for granted....a lack of sensitivity to this issue would shut off the open communication."

"The hilltop at which the college sits serves as a physical and metaphorical barrier between more privileged students who pay upwards to $\$ 50,000$ in tuition and the [local] poorer townsfolk."

"I had the preconceived notion that they would resent me due to my privilege. Since [this town] is a rural area with low SES, most of the clients work full time and their yearly income might be one fraction of [the college's] tuition."

Notably, several students reflected on learning about how vulnerable individuals are marginalized on multiple levels - a PPD-related topic tied to domestic violence and mental health. One student commented:

As I learned more about their economic situations, this silent judgment regarding their decisions to stay morphed into the understanding that economic independence from the abusive partners is not easily attainable.... It was at this point that I truly realized to what extent I have been looking at this situation from my place and perspective in society rather than theirs.

Another student noted:

The most important thing I learned are the structures of power and privilege that play in domestic violence situations. I am from an upper-middle class family in a nice suburban neighborhood. I have a loving family with parents in a healthy relationship. I have a large support network of friends and family members that I could turn to in any situation. I attend college which provides me with an education and resources to promote my mental and physical health. It seems that the only way in which I am unprivileged is being female, which certainly makes me more susceptible to domestic violence. While none of my positions of privilege protect or exempt me from experiencing domestic violence, my time at women's services made me realize that these privileges would make it far easier for me to escape violent situations.... This CSL experience has sparked my interest in legal advocacy work for domestic violence. I am in the process of applying for an internship to do work on policy writing and domestic violence advocacy. 
Paired-samples t-tests were completed on the MASQUE and revealed changes in the expected direction pre- to -posttest, though none reached statistical significance. An independent-samples t-test revealed a significant difference in scores for males $(M=17.41, S D=0.84)$ and females $(M=15.50, S D=$ $0.33 ; t(43)=-2.11, p=0.046$, two-tailed) on the Act subscale post-test, meaning males scored higher on the Act subscale compared to females. The effect size was moderate, $d=0.64$.

In summary, the analysis and review of student comments provided a richer picture of the CSL experience than would have been apparent in the results from the survey instruments. The comments provided specific, individualized examples of how students were impacted by the CSL experience, which is difficult to quantify, generally.

\section{Community Partner Individual Interviews}

In addition to enhancing student outcomes, CSL also benefits the local community providers. Therefore, the local partners were interviewed to explore the impact of CSL and their experiences. All of the CSL partners indicated satisfaction with the CSL students and program. When asked about the benefits, three overall themes emerged: the students get "real world experiences," they bring new energy and ideas to the sites, and they appreciate the extra help. For example, one provider commented:

I think that it gives the students a realistic perspective of what mental health truly is, and I think, unfortunately, many students ... are not given that realistic experience and they have a very jaded view on what mental health is and what they would really be doing, and I think it really normalizes what mental health is and makes the field more real to them. And it also gives them that chance to say, "You know what, this is for me," or "This really isn't for me."

Another provider shared the following:

Frankly it is part of my favorite things I do here. The students are fun and bring a different energy, and we currently enjoy having them. I guess I'll speak for myself, but I consistently see a good quality in them and they are excellent young people. Sometimes they need a little guidance, but we all did at that age. Seeing the relationships that they make with the members, because this is kind of a hands-on place. It's difficult to come in here and not engage or speak to anyone-I guess you could if you really didn't have to or want to- but usually members come up to you and talk you. It's neat to watch those relationships develop.

The two biggest challenges reported in the interviews were that the students were "over-involved," resulting in difficulties in scheduling, and the challenge of providing relevant experiences that would not intrude on the therapeutic process occurring at the sites. For example, one provider commented:

One challenge of the CE partnership in a small, mental health practice is the trickiness of trying to get all the students in on an individual session or group session at least once to experience what that is like. The issues of confidentiality and patients feeling uncomfortable with strangers sitting in on their sessions often makes it difficult for us to get all the students in at least once.

Most of the CSL providers had worked with college students in the past, had "high expectations" of the students, and "appreciate[d] what the college does for the community."

In fact, the CSL partnership enhanced most of the community partners' perceptions of the students, as one partner highlighted:

I know it is a private college, and very expensive. I know they're probably not paying for it themselves. So, I mean, I think it's a good experience for them to be in the real world. So close to their backyard with a lot of struggle that they are not familiar with. Very different from where most of these kids come from.

Another comment highlighted the uniqueness of the CSL experience: "It reminded me of how lucky [the college] students are to go to school in a small town where there are these opportunities where we can shadow professionals in the community without even having a bachelor's degree yet!" 


\section{Discussion}

The purpose of this mixed-methods study was to examine the impact of CSL in a rural community on 45 undergraduate students in a clinical psychology course. The goals were to provide an opportunity to develop a new contextualized grounded theory or understanding of the phenomenon of CSL in a rural community with undergraduate psychology students and to improve practice. Grounded theory allows for important concepts to emerge from the data, moving toward theory in the specific context in which the data were collected (Strauss \& Corbin, 2008). However, it is important to note that grounded theory is a neverending process of knowing (Dey, 2012). The results of this study add to the existing literature on the positive outcomes of CSL and provide a framework for a specific undergraduate course, while addressing some of the challenges associated with implementing CSL in a rural community. Consistent with previous research, students indicated that the CSL experience helped their learning and application of course concepts; however, this study's findings were also in line with others in which CSL did not result in changes in student outcomes in relation to PPD and empathy (Bringle \& Steinberg, 2010; Holsapple, 2012; Jacobson et al., 2011; Warren, 2012).

It is important to note that any changes in students might continue to develop, or even emerge, long after the CSL experience. In addition, any changes may have resulted from the students' experiences at their respective sites or from their critical reflections in the classroom, demonstrating the dynamic process of this framework (Whitley, 2014).

\section{CSL and Academic and Career Outcomes}

Research has supported that CSL offers students a deeper understanding of theoretical concepts, provides opportunities to apply theoretical concepts, improves academic outcomes, and enhances students' criticalthinking skills (Celio et al., 2011; Jacobson et al., 2011; Kuh, 2008; O'Neill, 2012; Yeh, 2010). The qualitative results from this study revealed that, overall, students indicated that the CSL helped them better understand lectures, readings, and key course concepts.

Unique to this study, the qualitative responses indicated that students made several connections related specifically to working in a rural area-for example, navigating ethical concerns, such as dual relationships and burnout, and the lack of resources available in rural communities. The CSL allowed students to experience directly issues specific to working in rural mental health, an element that would be missing from a traditional lecture-based course.

CSL also provides students the opportunity, at an ideal time in their undergraduate education, to clarify, explore, and validate their career plans (Yeh, 2010), and to develop a more practical understanding of the mental health field. This finding was also reflected in student comments and the CSL provider interviews. As one student commented, "I was also given a very good insight in the field I am hoping to work in." Another student reflected:

During my time at [the CSL site] I have learned a great deal about theory and the skills needed to successfully interact with a client. My knowledge of the traumas and situations that can affect a child's life has grown exponentially. I feel as though I now have a more holistic view of the social (including power, privilege and difference), familiar, geographic, and ethical issues that can affect children. I have learned a lot about the clinical setting, the various roles of the therapist, and most importantly the fact that the world of clinical psychology is attainable.

\section{CSL and Personal Outcomes}

CSL has been linked positively to student personal development (Astin \& Sax, 1998; Eyler \& Giles, 1999). The qualitative responses in this study indicated that some of the student participants this achieved this outcome. Student comments suggested that students experienced personal growth as a result of the CSL. The following comment reflects this outcome, highlighting the importance of this opportunity at the undergraduate level: 
Originally, I thought that we were going to be doing some sort of volunteer work, but the CSL sites taught me so much that I wouldn't have learned without this opportunity. I think it was a unique experience that I never thought I would have had the chance to participate in, especially being an undergraduate student.

Another comment, from a student's final paper, reflects the personal growth that occurred in the short time of the CSL experience:

I found myself making assumptions about their background and had to consciously tell myself to not make those assumption and to simply listen to their stories. I realized how hard it is to contradict your own preconceived notions and sometimes your own instincts. As discussed in [the textbook] the true test of unconditional positive regard comes with the clients whose behaviors and attitudes really challenge the therapist's beliefs.

Such reflections support the importance of a CSL course in an undergraduate psychology curriculum to enhance students' personal development. Future studies might consider a specific survey to address this outcome.

\section{CSL and Social and Civic Outcomes}

Research has supported that CSL helps to improve communication and interpersonal skills, create a civic identity, and increase commitment to social responsibility (Yeh, 2010; Youniss, 2009). One of the course goals in this study was to enhance empathy, which, as noted earlier, is central to enhancing helping relationships and diversity competencies. This outcome was measured both directly through the IRI and indirectly in the open responses. In their qualitative remarks, students agreed that the CSL assisted in their understanding of the course and in applying the course content to everyday life. When examining the results of the IRI, the only significant finding was that females scored higher than males on the EC subscale, post-CSL experience. These results are consistent with social stereotypes and with earlier findings that females often score higher on self-reports of empathy (Davis \& Franzoi, 1991; De Corte et al., 2007).

A unique finding in this study was that the CSL allowed students to feel connected with the rural community and to break down some of the stereotypes held about rural residents, perhaps demonstrating increased empathy. For example, during a class discussion, the students talked about how the "locals or townies" were perceived by some of the local college students, perceptions that were often negative. After the CSL, students revealed that had a better appreciation for the local community and community members. The partner interviews also highlighted this sentiment; one interviewee remarked that the CSL provided students with the opportunity to learn about the struggles of some of the local community members.

\section{CSL and Diversity and Multicultural/Intercultural Outcomes}

Previous research has found that CSL increases awareness of stereotypes, privilege, and tolerance for diversity, reduces stereotypes, and increases students' awareness of privilege (Catlett \& Proweller, 2011; Jones et al., 2011; Williams \& Melchiori, 2013). In this study, the only significant finding from the MASQUE was that males scored higher on the Act subscale than females, post-CSL experience. It should be noted that few instruments have been developed to measure constructs related to PPD, and the Act subscale of the MASQUE has demonstrated low reliability in the literature (Munroe \& Pearson, 2006), as it did in the current study. One explanation for the lack of significant findings could be the limited amount of diversity experiences at the CSL sites. As mentioned, the community is a small, rural, homogeneous area comprising predominantly European Americans. However, many students interacted with individuals who were from a different socioeconomic group than their family of origin, and other less obvious diversity issues were addressed through readings, reflections, and discussion in class. For example, as one student shared:

Hearing the [client] stories.... I was fortunate enough to have a stable home life growing up, I still have a stable home life now, sleeping with enough food, water, support in my life to be where I am today.... [L] earning from them was an experience unlike any other. 
16 | International Journal of Research on Service-Learning and Community Engagement

Another explanation could be that students became more aware of PPD issues and their limitations in knowledge throughout the class experience, thus effecting post-test scores; that is, perhaps students learned that they did not know as much as they originally thought. Finally, it may be that significant change is not evident after just one semester and requires gradual development. Follow-up surveys that are psychometrically sound, administered over time, may allow for a better assessment of long-term changes.

\section{Final Thoughts and Recommendations}

The following recommendations address some practical issues or "lessons learned" over the four semesters of the CSL course, moving from broad considerations in implementing CSL to specific suggestions related to implementing CSL in a rural area.

In general, when developing a CSL course, it is important to balance the increased time commitment and demands of the course for students. The students in this study attended a highly selective college and were often over-involved in academics and extracurricular activities. This concern was reflected by partner interviewees, who indicated that scheduling conflicts were a challenge. To address the demands and time commitment of the CSL course, the instructor eliminated an entire textbook from the syllabus that had been used in previous semesters to compensate for the addition of the CSL component. In addition, students need to be convinced of the importance of this experience and perhaps reminded that the experience is an opportunity, not just a class requirement.

Throughout the semester, it became apparent that students sometimes had difficulty practicing critical reflection. For some, this was a new way of learning and thinking, and it seemed that the students had trouble making explicit connections from the course to their CSL experiences. One student commented, "Connecting the class and sites can be done, but it is not something that is actively in my head while at my site." Because the instructor was confident that there were connections to be made, more inclass time discussing, reflecting, and engaging in meta-teaching and scaffolding was warranted. It seemed that the students placed in the "non-clinical" sites had more difficulty connecting to clinical concepts; however, they did recognize issues related to PPD. Therefore, devoting more time to helping students make explicit connections through classroom discussions and more clinically specific sites might be warranted.

Additionally, some sites require students to be more proactive and self-motivated than others, and setting those expectations early on with students is important. In this study, the instructor continuously reminded the students that the benefits and learning opportunities of the CSL experience would be enhanced by the amount of effort they put forth.

Institutional support for both time and resources might also help improve the success and positive outcomes of a CSL course. There is a considerable up-front time investment in setting up a CSL course, and access to additional resources could help manage these challenges and strains put on faculty. Many institutions are implementing a CSL requirement in the curriculum for all students and should support faculty in developing courses that meet those institutional demands. Finally, institutions might consider structuring multiple CSL experiences into the curriculum, as many of CSL outcomes are developmental and ongoing (Jameson et al., 2008).

Regarding recommendations specific to implementing CSL in a rural area, it is very important to set the CSL expectations early and to repeat them often to students in order to preserve the partnerships forged with local community providers. Research has indicated that rural communities are tight-knit, are often suspicious of outsiders, and engage in deep collaboration; therefore, professional relationships may be even more important in rural areas than urban areas (Curtain \& Hargrove, 2010; Paulson \& Casile, 2014; Paulson, Casile, \& Jones, 2015). The instructor repeated this often to the students and provided literature to support these statements. In addition, the CSL partners indicated that they had forged relationships with the college and recognized the mutual benefits of those relationships. Specifically, the providers noted that the students breathed energy and new ideas into their work with the community, and provided extra hands at sites that are already understaffed. 
A second implication of the results of this study is that implementing more CSL in rural areas can encourage students to stay and work in rural communities, areas that are already experiencing difficulty recruiting and retaining mental health professionals. Through CSL, students can experience the benefits of working in rural areas, such as a lower cost of living, a general sense of safety, and a slower pace of life (Paulson, 2010). Several students commented that the CSL helped them "connect with the rural community" from which they had previously felt disconnected. Facilitating these networks and collaborative relationships is necessary for effective work as a mental health professional and is even more apparent in smaller communities.

It is also important to ask students if they have reliable transportation and to remind them of the time commitment needed for travel. Rural areas typically do not have adequate public transportation and often lack the infrastructure to provide reliable transportation to mental health facilities. Therefore, instructors should try to link students who do not have transportation with those who do or place students without transportation at sites within walking distance of the campus.

\section{Limitations and Future Research}

In order to maintain the integrity of this research, it is imperative to consider the limitations of the study. One limitation to this research is the degree to which the findings can be transferred to other students, courses, or contexts. This research included a purposeful convenience sample that may have resulted in bias. It is hoped that this review described the context of this study and the course in a way that allows other instructors to determine if the findings are applicable or adaptable to their specific course. The survey instruments utilized self-report measures, which can have their benefits, but it is possible the study participants over- or underestimated their responses in order to conceal vulnerabilities or enhance social desirability. However, anonymity in the surveys was maintained and likely did not negatively influence outcomes. Due to the nature of the methodology used, there might have also been a repeated-testing effect; therefore, future studies might consider using a comparative group and randomly assign participants to CSL versus non-CSL groups. Another limitation related to action research is the potential for researcher bias, considering the author's dual role as researcher and instructor. Students also self-selected into the class, which might indicate a personal investment in the topic or in CSL. Another challenge is that the projects and the range of CSL experiences varies each semester, potentially influencing the outcomes (Ma \& Lo, 2016).

Clearly, larger studies, conducted over several more semesters with control groups, are warranted. In addition to the previous recommendations, longitudinal studies are recommended since the outcomes measured in this study might not emerge until long after the CSL experience (Eyler \& Giles, 1999). A thematic analysis of the student weekly reflections could further validate the qualitative results or provide direction for more effective quantitative measures.

In conclusion, the results of this study demonstrate that students grew in academic, personal, civic, and diversity domains, and they support the implementation of CSL in any pre-professional course. In addition, students reported experiences that were unique to working in the rural context. Perhaps most importantly, the CSL provided the students with a unique undergraduate experience difficult to quantify, as captured by this student reflection:

While writing this paper, and throughout this semester, there has been one recurring thought that I cannot shake. I need more CSL. I need more engaging experiences outside of my comfort zone, communities that make me feel uncomfortable, and community that make me check my power and privilege....[T]his experience has exposed me to how much I do not know and how much I want to learn.

\section{Author Note}

Lauren R. Paulson, Department of Psychology, Allegheny College. 
18 | International Journal of Research on Service-Learning and Community Engagement

\section{Correspondence}

Correspondence regarding this article should be addressed to Lauren R. Paulson, Assistant Professor, Department of Psychology, Allegheny College, Carnegie Hall 202, 520 North Main Street, Meadville, PA 16335. Phone: (814) 332-6029. E-mail: lpaulson@ @allegheny.edu

\section{References}

American Psychological Association. (2013). APA guidelines for the undergraduate psychology major: Version 2.0. Retrieved from https://www.apa.org/ed/precollege/about/psymajor-guidelines.pdf

Aronson, K. R., Webster, N. S., Reason, R., Ingram, P., Nolan, J., Mitchell, K., \& Reed, D. (2005). Using randomized control field trials in service learning research. In S. Root, J Callahan, \& S. Billig (Eds.), Improving service-learning practice: Research on models to enhance impacts (pp. 141-165). Greenwich, CT: Information Age Publishing.

Astin, A. W., \& Sax, L. J. (1998). How undergraduates are affected by service participation. Journal of College Student Development, 39, 251-263.

Ash, S. L., \& Clayton, P. H. (2009). Generating, deepening, and documenting learning: The power of critical reflection in applied learning. Journal of Applied Learning in Higher Education, 1(1), $25-48$.

Association of American Colleges and Universities. (2005). Achieving equitable educational outcomes with all students: The institution's roles and responsibilities. Washington, DC: Author. Retrieved from http://www.aacu.org/inclusive excellence/documents/ Bauman et al.pdf

Barbopoulos, A., \& Clark, J. M. (2003). Practicing psychology in rural settings: Issues and guidelines. Canadian Psychology, 44(4), 410-424.

Billig, S. H., \& Furco, A. (2002). Supporting a strategic service-learning research plan. In S. Billig \& A. Furco (Eds.), Service-learning through a multidisciplinary lens (pp. 217-230). Greenwich, CT: Information Age Publishing.

Bringle, R. G., \& Steinberg, K. (2010). Educating for informed community involvement. American Journal of Community Psychology, 46, 428-441.

Bronfenbrenner, U. (1979). The ecology of human development. Cambridge, MA: Harvard University Press.

Bronfenbrenner, U. (Ed.) (2005). Making human beings human: Bioecological perspectives on human development. Thousand Oaks, CA: Sage Publications.

Campbell, C. D., Kearns, L. A., \& Patchin, S. (2006). Psychological needs and resources as perceived by rural and urban psychologists. Professional Psychology: Research and Practice, 37(1), 45-50.

Catlett, B. S., \& Proweller, A. (2011). College students' negotiation of privilege in a community-based violence prevention project. Michigan Journal of Community Service Learning, 18(1), 34-48.

Celio, C. I., Durlak, J., \& Dymnicki, A. (2011). A meta-analysis of the impact of service-learning on students. Journal of Experiential Education, 34(2), 164-181.

Clark, M., McKague, M., McKay, S., \& Ramsden, V. (2015). Deeper learning through service: Evaluation of an interprofessional community service-learning program for pharmacy and medicine students. Journal of Interprofessional Practice and Education, 5(1), 1-25.

Cliffordson, C. (2002). The hierarchical structure of empathy: Dimensional organization and relations to social functioning. Scandinavian Journal of Psychology, 43(1), 49-59.

Conway, J. M., Amel, E. L., \& Gerwien, D. P. (2009). Teaching and learning in the social context: A meta-analysis of service-learning's effects on academic, personal, social, and citizenship outcomes. Teaching of Psychology, 36, 233-245.

Crabtree, R. D. (2008). Theoretical foundations for international service-learning. Michigan Journal of Community Service Learning, 15(1), 18-36.

Creswell, J. W. (1994). Research design: Qualitative and quantitative approaches. Thousand Oaks, CA: Sage. 
Curtain, L., \& Hargrove, D. S. (2010). Opportunities and challenges of rural practice: Managing self amid ambiguity. Journal of Clinical Psychology, 56, 549-561.

Davis, M. H. (1980). A multidimensional approach to individual differences in empathy. JSAS Catalog of Selected Documents in Psychology, 10, 85-104.

Davis, M. H., \& Franzoi, S. L. (1991). Stability and change in adolescent self-consciousness and empathy. Journal of Research in Personality, 25(1), 70-87.

De Corte, K., Buysse, A., Verhofstadt, L., Roeyers, H., Ponnet, K., \& Davis, M. (2007). Measuring empathic tendencies: Reliability and validity of the Dutch version of the Interpersonal Reactivity Index. Psychologica Belgica, 47(4), 235-260.

Deeley, S. J. (2010). Service-learning: Thinking outside the box. Active Learning in Higher Education, 11(1), 43-53.

Denzin, N. K., \& Lincoln, Y. S. (Eds.). (2011). The Sage handbook of qualitative research. Thousand Oaks, CA: Sage.

Dewey, J. (1938). Experience and education. New York: Simon \& Schuster.

Dey, I. (2012). Grounding grounded theory: Guidelines for qualitative inquiry. London: Academic Press.

Eyler, J., \& Giles, D. E., Jr. (1999). Where's the learning in service-learning? San Francisco: JosseyBass.

Eyler, J. S., Giles, D. E., Jr., Stenson, C. M., \& Gray, C. J. (2001). At a glance: What we know about the effects of service learning on college students, faculty, institutions and communities, 1993-2000 ( $3^{\text {rd }}$ ed.). Nashville, TN: Vanderbilt University.

Fox, J. C., Blank, M., Rovnyak, V. G., \& Barnett, R. Y. (2001). Barriers to help seeking for mental disorders in a rural impoverished population. Community Mental Health Journal, 37(5), 421-436.

Gale, J. A., \& Lambert, D. (2006). Mental healthcare in rural communities: The once and future role of primary care. North Carolina Medical Journal, 67(1), 66-70.

Gale, J. A. \& Deprez, R. D. (2003). A public health approach to the challenges of rural mental health service integration. In B. Stamm (Ed.), Rural behavioral health care: An interdisciplinary guide (pp. 95-108). Washington, DC: American Psychological Association.

Grant, B. F., Goldstein, R. B., Saha, T. D., Chou, S. P., Jung, J., Zhang, H., ... \& Hasin, D. S. (2015). Epidemiology of DSM-5 alcohol use disorder: Results from the National Epidemiologic Survey on Alcohol and Related Conditions III. JAMA Psychiatry, 72(8), 757-766.

Greenson, R. R. (1967). The working alliance and the transference neuroses. Psychanalysis Quarterly, 34, 155-181.

Helbok, C. M. (2003). The practice of psychology in rural communities: Potential ethical dilemmas. Ethics and Behavior, 13(4), 367-384.

Holsapple, M. A. (2012). Service-learning and student diversity outcomes: Existing evidence and directions for future research. Michigan Journal of Community Service Learning, 18(2), 5-18.

Jacobson, J., Oravecz, L., Falk, A., \& Osteen, P. (2011). Proximate outcomes of service-learning among family studies undergraduates. Family Science Review, 16(1), 22-33.

Jameson, J., Clayton, P. H., \& Bringle, R. G. (2008). Investigating student learning within and across linked service-learning courses. In M. Bowden, S. Billig, \& B. Holland (Eds.), Advances in service-learning research: Scholarship for sustaining service-learning and civic engagement (pp. 3-27). Greenwich, CT: Information Age Publishing.

Jones, D., McAllister, L., \& Lyle, D. (2016). Community-based service-learning: A rural Australian perspective on student and academic outcomes of participation. International Journal of Research on Service-Learning and Community Engagement, 4(1), 181-197

Jones, S. R., Robbins, C. K., \& LePeau, L. A. (2011). Negotiating border crossing: Influences of social identity on service-learning outcomes. Michigan Journal of Community Service Learning, 17(2), 27-42.

Keen, C., \& Hall, K. (2009). Engaging with difference matters: Longitudinal student outcomes of cocurricular service-learning programs. Journal of Higher Education, 80(1), 59-79. 
20 International Journal of Research on Service-Learning and Community Engagement

Kolb, D. A. (1984). Experiential learning: Experience as the source of learning and development. Englewood Cliffs, NJ: Prentice-Hall.

Kuh, G. D. (2008). Excerpt from high-impact educational practices: What they are, who has access to them, and why they matter. Washington, DC: Association of American Colleges and Universities.

Larson, J. E., \& Corrigan, P. W. (2010). Psychotherapy for self-stigma among rural clients. Journal of Clinical Psychology, 66, 524-546.

Lemieux, C. M., \& Allen, P. D. (2007). Service learning in social work education: The state of knowledge, pedagogical practicalities, and practice conundrums. Journal of Social Work Education, 43(2), 309-326.

Ma, C. H. K., \& Lo, D. F. Y. (2016). Service-learning as an independent course: Merits, challenges, and ways forward. International Journal of Research on Service-Learning and Community Engagement, 4(1), 39-52.

Mohatt, D. F., Bradley, M. M., Adams, S. J., \& Morris, C. D. (2006). Mental health and rural America: 1994-2005. Washington, DC: U.S. Department of Health and Human Services, Health Resources and Services Administration, Office of Rural Health Policy.

Munroe, A., \& Pearson, C. (2006). The Munroe Multicultural Attitude Scale Questionnaire: A new instrument for multicultural studies. Educational and Psychological Measurement, 66(5), 819-834.

O'Neill, N. (2012). Promising practices for personal and social responsibility: Findings from a national research collaborative. Washington, DC: Association of American Colleges and Universities.

Ozorak, E. W. (2003). Integrating service learning into psychology courses. APS Observer, 16(11), 21-22.

Paulson, L. (2010). The lived experience of supervisors in rural settings. Retrieved from https://www.counseling.org/docs/default-source/vistas/the-lived-experience-of-supervisors-inrural-settings.pdf

Paulson, L. R., \& Casile, W. J. (2014). Building Bridges: A pilot program for training and support of rural supervisors. The Clinical Supervisor, 33, 1-24.

Paulson, L. R., Casile, W. J., \& Jones, D. (2015). Tech it out: Implementing an online peer consultation network for rural mental health professionals. Journal of Rural Mental Health, 39(3-4), 125-136.

Sawyer, D., Gale, J., \& Lambert, D. (2006). Rural and frontier mental health and behavioral health care: Barriers, effective policy strategies, best practices. Waite Park, MN: National Association of Rural Mental Health. Retrieved from https://digitalcommons.usm.maine.edu/cgi/viewcontent.cgi?referer=https://www.google.com/\&ht tpsredir $=1 \&$ article $=1051 \&$ context=behavioral_health

Schank, J. A., \& Skovholt, T. M. (2006). Ethical practice in small communities: Challenges and rewards for psychologists. Washington, DC: American Psychological Association.

Slavkin, M. L. (2007). Transforming education through service-learning. New Horizons in Education, 55(1), 107-122.

Smith, A. J. (2003). Rural mental health counseling: One example of practicing what the research preaches. Journal of Rural Community Psychology, 6(2).

Strauss, A., \& Corbin, L. (1998). Basics of qualitative research: Grounded theory procedures and techniques (2 $2^{\text {nd }}$ ed.). Thousand Oaks, CA: Sage.

U.S. Census Bureau. (2016a). A comparison of rural and urban America: Household income and poverty. Retrieved from https://www.census.gov/newsroom/blogs/randomsamplings/2016/12/a_comparison_of_rura.html

U.S. Census Bureau. (2016b). QuickFacts: Crawford County, Pennsylvania. Retrieved from http://www.census.gov/quickfacts/table/PST045215/42039

Wagenfeld, M. O. (2003). Portrait of rural and frontier America. In B. Stamm (Ed.), Rural behavioral health care: An interdisciplinary guide (pp. 33-40). Washington, DC: American Psychological Association. 
Warren, J. L. (2012). Does service-learning increase student learning?: A meta-analysis. Michigan Journal of Community Service Learning, 18(2), 56-61.

Weigel, D. J., \& Baker, B. G. (2002). Unique issues in rural couple and family counseling. The Family Journal: Counseling and Therapy for Couples and Families, 10, 61-69.

Werth, J. L., Hastings, S. L., \& Riding-Malon, R. (2010). Ethical challenges of practicing in rural areas. Journal of Clinical Psychology, 66(5), 537-548.

Whitley, M. A. (2014). A draft conceptual framework of relevant theories to inform future rigorous research on student service-learning outcomes. Michigan Journal of Community Service Learning, 20(2), 19-41.

Williams, W. R., \& Melchiori, K. J. (2013). Class action: Using experiential learning to raise awareness of social class privilege. In K. Case (Ed.), Deconstructing privilege: Teaching and learning as allies in the classroom (pp. 169-187). New York: Routledge.

Yeh, T.L. (2010). Service-learning and persistence of low-income, first-generation college students: An exploratory study. Michigan Journal of Community Service Learning, 16(2), 60-65.

Youniss, J. (2009). Why we need to learn more about youth civic engagement. Social Forces, 88(2), 971-975. 